See discussions, stats, and author profiles for this publication at:

http://www.researchgate.net/publication/279868987

\title{
Paranoia Predicts Outgroup Prejudice: Preliminary Experimental Data
}

ARTICLE in MENTAL HEALTH RELIGION \& CULTURE · JULY 2015

DOWNLOADS

7

\section{AUTHORS:}

\section{Barbara Lopes}

De Montfort University

8 PUBLICATIONS 62 CITATIONS

SEE PROFILE

\section{Rusi Jaspal}

De Montfort University

45 PUBLICATIONS 261 CITATIONS

SEE PROFILE
VIEWS

17 
This article was downloaded by: [89.153.112.192]

On: 31 July 2015, At: 07:33

Publisher: Routledge

Informa Ltd Registered in England and Wales Registered Number: 1072954 Registered

office: 5 Howick Place, London, SW1P IWG

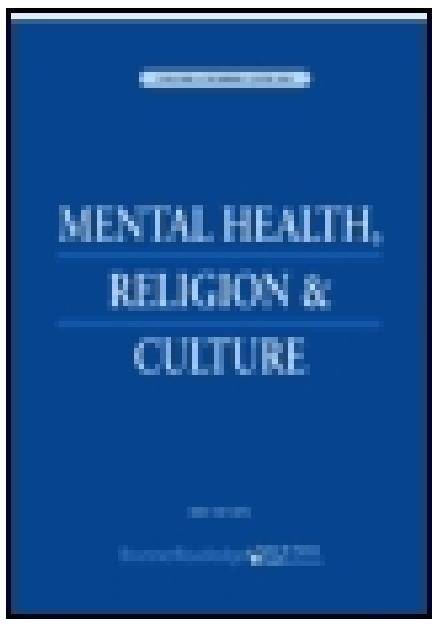

\title{
Mental Health, Religion \& Culture
}

Publication details, including instructions for authors and subscription information:

http:/ / www.tandfonline.com/loi/ cmhr20

\section{Paranoia predicts out-group prejudice: preliminary experimental data}

\author{
Barbara Lopes $^{a} \&$ Rusi J aspal ${ }^{a}$ \\ a School of Applied Social Psychology, De Montfort University, \\ Leicester LE19BH, UK \\ Published online: $30 \mathrm{~J}$ ul 2015.
}

CrossMark

$\underline{\text { Click for updates }}$

To cite this article: Barbara Lopes \& Rusi J aspal (2015): Paranoia predicts out-group prejudice: preliminary experimental data, Mental Health, Religion \& Culture, DOI: 10. 1080/13674676.2015.1065475

To link to this article: http:// dx. doi.org/ 10.1080/ 13674676. 2015. 1065475

\section{PLEASE SCROLL DOWN FOR ARTICLE}

Taylor \& Francis makes every effort to ensure the accuracy of all the information (the "Content") contained in the publications on our platform. However, Taylor \& Francis, our agents, and our licensors make no representations or warranties whatsoever as to the accuracy, completeness, or suitability for any purpose of the Content. Any opinions and views expressed in this publication are the opinions and views of the authors, and are not the views of or endorsed by Taylor \& Francis. The accuracy of the Content should not be relied upon and should be independently verified with primary sources of information. Taylor and Francis shall not be liable for any losses, actions, claims, proceedings, demands, costs, expenses, damages, and other liabilities whatsoever or howsoever caused arising directly or indirectly in connection with, in relation to or arising out of the use of the Content.

This article may be used for research, teaching, and private study purposes. Any substantial or systematic reproduction, redistribution, reselling, loan, sub-licensing, systematic supply, or distribution in any form to anyone is expressly forbidden. Terms \& 
Conditions of access and use can be found at http://www.tandfonline.com/page/termsand-conditions 


\title{
Paranoia predicts out-group prejudice: preliminary experimental data
}

\author{
Barbara Lopes and Rusi Jaspal* \\ School of Applied Social Psychology, De Montfort University, Leicester LE19BH, UK \\ (Received 27 March 2015; accepted 20 June 2015)
}

\begin{abstract}
This article examines the relationships between exposure to terrorism news and state social paranoia, death anxiety and Islamophobia. In two experiments we show that, contrary to previous research in this area, the terrorism news condition did not significantly increase state social paranoia, death anxiety and prejudice towards Muslims, but that paranoid thinking was the sole predictor of Islamophobia. Trait paranoia is associated with both poor well-being and with negative perceptions of Muslim competitive players - a form of interrelational prejudice. Results indicated that the frequency of paranoid thoughts mediates the relationship between death anxiety and anti-Muslim prejudice and trait paranoia is the main predictor of the negative perceptions of a Muslim competing player. This study elucidates new pathways to understanding terror management theory, by including paranoia as a type of thinking that predisposes individuals to be suspicious of salient out-groups.
\end{abstract}

Keywords: Islamophobia; prejudice; paranoia; death anxiety; social psychology; clinical psychology

\section{Introduction}

Prejudice towards Muslims, often referred to as "Islamophobia", is a pressing socio-psychological problem. Prior to the 9/11 terrorist attacks in New York, Muslims have faced stigma and discrimination - they have been viewed as a more vocal and potentially dangerous minority at risk of radicalisation, sympathetic to terrorism and generally unfaithful to the non-Muslim dominant society. The newspaper media, as well as other forms of media, have contributed to negative and threatening social representations of Muslims (Cinnirella, 2014; Jaspal \& Cinnirella, 2010). Moreover, research indicates that threat anticipation and mistrust promoted by the media are associated with increased paranoid thinking, namely that others maliciously try to cause harm (Freeman \& Freeman, 2008). What is the relationship between exposure to negative media reporting and prejudice? Do all readers of the British media respond to Islamophobic representations in the same way? Are we all susceptible to developing prejudice towards Muslims on the basis of what we read? This article addresses these questions by examining experimentally the potential links between negative representations of Muslims, paranoia, and Islamophobia.

\section{Media and prejudice}

People tend to rely on the mass media to form beliefs about minority groups. Analysts have shown that media representations of Muslims tend to be negative and to dwell upon themes of threat

\footnotetext{
*Corresponding author. Email: rusi.jaspal@gmail.com
} 
(Poole, 2002; Richardson, 2004). Saeed (2007) describes the prevalence of Islamophobia in the British media, suggesting that Muslims are depicted as the Other. Similarly, drawing upon Intergroup Threat theory (Stephan \& Stephan, 2000), Jaspal and Cinnirella (2010) argue that Muslims have recently been represented as posing a "hybridised" threat consisting of realistic and symbolic elements - they are simultaneously depicted as threatening the cultural norms, values and traditions of the White British majority, as well as posing a terrorist threat and, thus, jeopardising the survival of the majority group.

Various empirical studies have evidenced the link between media representations and the formation of stereotypes at an individual level (Johnson, Olivo, Gibson, Reed, \& AshburnNardo, 2009; Lester \& Ross, 2003). Cinnirella (2014) examined media effects on Islamophobia from an intergroup relations perspective drawing principally upon the social identity approach (Tajfel, 1982). In a between-groups experiment with British participants, Cinnirella, Leman, Hastings, and Whitbread (2009) showed that media articles that depicted Muslims as posing a significant threat to the British national in-group induced more negative attitudes towards Muslims than those articles that depicted Muslims as posing a less dire threat or no threat. Moreover, their results suggested that British national identification mediated the relationship between article type and Islamophobia in that those who were more identified with the nation tended to manifest more negative attitudes when they perceived Muslims as threatening their valued in-group. This work is consistent with the social identity tradition which suggests that out-group prejudice stems from one's self-categorisation as an in-group member and the perception of threat to that in-group. In contrast to this approach, terror management theorists have attempted to provide individual-level accounts of prejudice.

\section{Terror management and Islamophobia}

Terror Management Theory (TMT) (Greenberg, Pyszczynski, \& Solomon, 1986) explains why perceived threat from out-groups may induce prejudice and hostility towards them (see also Greenberg, Schimel, Martens, Solomon, \& Pyszczynski, 2001). TMT argues that individuals are inherently fearful of their own mortality and that reminders of their mortality activate "death anxiety". This in turn engenders defensiveness and out-group hostility in order to safeguard one's culture and world view (Yum \& Schenck-Hamlin, 2005). According to TMT, human beings retain a sense of continuity (which itself is jeopardised by death-related thoughts) by maintaining faith in world views that justify one's existence and cultural continuity.

TMT has been employed to examine prejudice against out-groups. In several experiments focusing upon anti-Arab sentiment, Das, Bushman, Bezemer, Kerkhof, and Vermeulen (2009) showed that participants exposed to media depicting terrorist events exhibited higher levels of death-related thoughts than those who were exposed to non-terrorism news. Similarly, McNaughton-Cassill, Novian, Holmes, and Smith (2009) found that the extensive news coverage of the 9/11 in New York attacks was associated with higher levels of death-related thoughts. Das et al.'s (2009) research suggested that death anxiety was positively correlated with anti-Arab prejudice, indicating that the media acted as a moderator between death anxiety and out-group prejudice. Although TMT has received considerable empirical support in the domain of prejudice, we wish to examine the potential role of paranoia, which has seldom been the focus of sociopsychological studies of intergroup relations. Paranoia, as a fear of others, may be related to death anxiety, which is characterised by constant intrusive thoughts about death (Templer, 1970). In other words, an exacerbated fear of death may be linked to the anticipation of malicious harm from others (Freeman et al., 2005). 


\section{Paranoia and prejudice}

Paranoia has scarcely been linked to prejudice research, and there are no studies that have linked it to TMT and intergroup relations. Paranoia can be defined as a relatively stable mode of thinking that can be observed in non-clinical populations and that is characterised by suspiciousness, feelings of ill will or resentment and beliefs in external control or influence (Fenigstein \& Vanable, 1992). This type of thinking builds upon interpersonal sensitivities (e.g., fear of how one appears to others) and ranges from common social anxiety fears (e.g., will other people accept me?) to conspiracy ideas (e.g., others are working together against me). Paranoia is thus characterised by the general belief that others are maliciously and intentionally trying to cause harm in some way (Freeman et al., 2005). This paranoid schema is thought to be determined by both genetic and environmental influences (Combs et al., 2007).

Existing research suggests that there should be an association between paranoid thinking and prejudice, in that excessive attentiveness to threat and harm from others may lead to increased suspicion of out-groups (Bhat, 2007; Combs et al., 2007). For instance, in a cross-sectional survey study, Rippy and Newman (2006) found a statistically significant relationship between perceived religious discrimination and sub-clinical paranoia among the Muslim Americans whom they surveyed, suggesting that perceived discrimination was associated with increased vigilance and suspicion towards out-groups. Similarly, it could be argued that majority group members who manifest sub-clinical paranoia will exhibit vigilance and suspicion towards out-groups that they perceive as threatening. More generally, Freeman and Freeman (2008) suggested that threatening media reports did indeed lead to heightened levels of paranoia among viewers. This research indicates an association between paranoia and prejudice, a relationship which the present studies seek to explore.

This research also suggests that paranoia may be detrimental for positive relations (Lopes \& Pinto-Gouveia, 2013) and for psychological well-being (e.g., issues with self-acceptance, see Bentall, Kinderman, \& Kaney, 1994). The paranoid individual may, due to their suspicion of other people's intentions, experience difficulties in developing interpersonal relationships. This is particularly acute if these relationships are situated in a competition scenario, since the individual is inclined to read "sinister intentions" in their competitor(s) (Gilbert, Boxall, Cheung, \& Irons, 2005). Since most ethnic/religious groups are in a state of competition for resources (Gilbert et al., 2005), it seems plausible to explore how different ethnic/groups would react to a Muslim competitor.

We thus developed experimental studies to explore how paranoid tendencies may lie at the heart of prejudice, poor well-being and negative perceptions during a competitive online game.

Accordingly, the following hypotheses are tested in these studies:

- In the first study, following Das et al. (2009) study, we predicted that terrorism news would induce elevated state social paranoia, death anxiety, cultural mistrust of Muslims and Islamophobia.

- Since paranoia is associated with both prejudice and death anxiety (Freeman \& Freeman, 2008), we would expect paranoia to mediate the relationship between death anxiety and anti-Muslim prejudice.

- In the second study, we expect trait paranoia to predict the variance of the negative perceptions concerning a Muslim competitive player.

\section{Experiment 1}

The aim of experiment 1 was to replicate Das et al.'s (2009) study and to test the effects of news conditions on Islamophobia as well as death anxiety. A novel concern in this experiment is the effect of paranoid thoughts on Islamophobia. 


\section{Method}

\section{Participants}

Sixty De Montfort University undergraduate students participated in this study. Seven participants were removed from the final data set due to withdrawal or incomplete data, leaving a total sample size of 53. The age range of participants was $18-29(M=21.4, \mathrm{SD}=3)$. There were 35 females and 18 males. Thirty participants were randomly allocated to the "terrorism" condition, and 23 to the "non-terrorism" condition. Given the focus of the study, only non-Muslims were included in the sample. Participants described themselves as atheist (50\%), Christian (30\%) and Sikh (20\%). None of the respondents reported having been affected by acts of terrorism (either personally or via friends or relatives). The study received ethical approval from the De Montfort University Research Ethics Board and was consistent with the British Psychological Society Code of Human Research Ethics (BPS Ethics Committee, 2009).

\section{Instruments}

The Paranoia Checklist (Freeman et al., 2005) was used to assess the participant's level of paranoia before their exposure to the news broadcast. The 18-item checklist measured the frequency, conviction and distress of a paranoid thought, with statements such as "I need to be on my guard against others", scored from 1 to 5. The scores were calculated to ascertain the participant's frequency, conviction and distress of paranoid thoughts, and higher scores indicated higher levels across all dimensions. The internal reliability of the scales was excellent: frequency, $\alpha=.86$, conviction, $\alpha=.96$ and distress, $\alpha=.92$.

The State Social Paranoia Scale (Freeman et al., 2007) was used to assess the level of paranoia following the news broadcast. The scale consists of 20 positive, neutral and negative statements, for example, "Someone has good intentions towards me". Participants expressed agreement from 1 to 5. A total score of state social paranoia was calculated with a higher score indicating higher state social paranoia. The internal reliability of the scale was moderate, $\alpha=.66$.

The Death Anxiety Scale (Templer, 1970) was used to assess the level of anxiety the participant feels in relation to death. This included two scales, the first featuring 15 items, such as "I am really scared of having a heart attack". Participants were asked to circle " $T$ " if the statement was true or mostly true of them, or " $F$ " if the statement was false or mostly false. This part of the scale is scored by calculating the number of times the participant circles " $T$ ". The next part of the Death Anxiety Scale has 17 items, such as "I get depressed when I think about death". Participants expressed agreement from 1 to 5 . A higher score indicates higher death anxiety. The internal reliability of the scale was good, $\alpha=.82$.

The Cultural Mistrust Inventory (Terrell \& Terrell, 1981) was adapted to measure mistrust towards Muslims. The revised version of the scale consisted of 41 items, such as "Muslims are usually fair to all people regardless of religion". Participants expressed agreement from 1 to 5. A higher score indicated a higher level of mistrust towards Muslims. The internal reliability of the scale was excellent, $\alpha=.97$.

The Islamophobia Scale (Lee, Gibbons, Thompson, \& Timani, 2009) was used to ascertain the level of prejudice towards Muslims. The scale contained 16 items, such as "Islam is a dangerous religion". Participants expressed agreement from 1 to 5. A higher score indicated increased prejudice towards Islam. The internal reliability of the scale was excellent, $\alpha=.95$.

\section{Experimental procedure}

Participants were randomly assigned to either the "terrorism" condition or the "non-terrorism" condition. The "terrorism" news condition presented a video lasting five minutes which depicted 
the bomb attacks on the London Underground on 7 July 2005. The suspects in the video were all Muslims. The video in the "non-terrorism" news (control) condition depicted a news broadcast of the effects of technology on children's sleeping patterns.

Participants first completed the Paranoia Checklist and the Implicit Association Test (IAT) in an individual research cubicle. The IAT has been demonstrated to be an effective measure of implicit, subconscious prejudice (Das et al., 2009), while avoiding certain demand characteristics associated with explicit measures of attitudes and prejudice. The SuperLab programme (Version 4.5) was used to run the IAT (Greenwald, McGhee, \& Schwartz, 1998), which was re-designed to measure negative implicit attitudes towards Muslims. The IAT included 85 trials; the first 20 trials contained a single name in the middle of the page, a non-Muslim British-sounding name (e.g., "Johnny") or a Muslim-sounding name (e.g., "Ahmed"). The next 20 trials contained a positive word (e.g., "joy") or a negative word (e.g., "hatred") in the centre of the page. The four categories, "British", "Muslim", "positive" and "bad", were situated in the top left- and right-hand corners of the screen. The next 40 trials on the IAT were a mixture of the four categories. Each trial was randomly shown to each participant to avoid order effect bias. Each participant was required to assign certain words to the correct category by pressing either the "E" or "I" key to indicate "left" or "right". On the first test, participants were required to press a specific button if the word was a "British-sounding name or positive", and press another if the word was a "Muslim-sounding name or negative". The process was then reversed - "British-sounding name or negative" and "Muslim-sounding name and positive". After the IAT, participants saw the news and completed the State Social Paranoia Scale, the Death Anxiety Scale, Cultural Mistrust of Muslims Inventory, and the Islamophobia Scale. They were then debriefed and thanked for their participation.

\section{Results}

We computed the difference in reaction times between the two test blocks (British-sounding names and positive words vs. Muslim-sounding names and negative words) and (British-sounding names and negative words vs. Muslim-sounding names and positive words) as a measure of prejudiced attitudes against Muslims.

We also examined the distribution of the scores of the different dimensions of the Paranoia Checklist. The results we obtained for the different dimensions of the Paranoia Checklist were largely consistent with what was found by Freeman et al. (2005) although slightly higher: frequency of paranoid thoughts: $M=18.77, \mathrm{SD}=8.63$, minimum value $=18$, maximum value $=$ 56,25 th percentile $=23,50$ th percentile $=27,75$ th percentile $=33.50$ (range 18-90); conviction of paranoid thoughts: $M=37.68, \mathrm{SD}=17.83$, minimum value $=18$, maximum value $=90,25$ th percentile $=24.50,50$ th percentile $=30,75$ th percentile $=48$ (range 18-90) and distress of paranoid thoughts: $M=18.60, \mathrm{SD}=12.78$, minimum value $=0$ and maximum value $=55,25$ th percentile $=6.50,50$ th percentile $=18,75$ th percentile $=50$ (range $0-70)$.

The skewness of the distribution of the frequency and conviction of paranoid thoughts was slightly to the left but not as much as observed in the original study by Freeman et al. (2005) (1.2 and 1.4 with a kurtosis of 1.04 and 1.08 for frequency and conviction, respectively). The distribution of the distress of paranoid thoughts was normal with a skewness of .75 and kurtosis of .30. A Kolmogorov-Smirnov $(\mathrm{K}-\mathrm{S})$ test was performed to test the normality of the dimensions of the paranoia checklist in our sample. Results showed that the data were normally distributed for the frequency of paranoid thoughts $(Z=1.23, p=.098)$, the conviction of paranoid thoughts $(Z=$ $1.51, p=.078)$ and the distress of paranoid thoughts $(Z=.61, p=.85)$.

A one-way ANOVA was performed to examine the effects of the terrorism news on the dependent variables. There were no statistically significant effects of the terrorism news condition on state social paranoia, $F(1,52)=.53, p=.47, d=.20$; death anxiety, $F(1,52)=.15, p=.70$, 
$d=.11$; on cultural mistrust of Muslims, $F(1,52)=.22, p=.64, d=13$; or on Islamophobia, $F(1,52)=.08, p=.78, d=.08$ (Table 1). This suggested that the terrorism news condition did not have an effect on Islamophobia and death anxiety, as previously observed in the literature. Indeed, the effect of the independent variable on death anxiety was considerably smaller $(d=.11)$ to the one presented by Das et al. (2009) $(d=.51)$.

When examining the correlations between the main variables, we found a positive correlation between paranoia (frequency) and cultural mistrust $r=.49, n=53, p<.001$ and Islamophobia $r=.39, n=53, p<.005$, suggesting an association between these variables. Moreover, the paranoia dimensions of frequency and distress were positively correlated with death anxiety $(r=.34, n=53, p<.005$ and $r=.28, n=53, p<.05$, respectively). As expected, given the similarity of the two constructs, there was also a strong, positive correlation between cultural mistrust of Muslims and Islamophobia, $r=.72, n=53, p<.001$ (see Table 2).

We used structural equation modelling to analyse the direct and indirect effects of death anxiety as an independent variable impacting anti-Muslim prejudice measured by cultural mistrust of Muslims and Islamophobia. Linear regressions showed that death anxiety did not itself predict cultural mistrust of Muslims $\left(R^{2}=.040 ; F(1,52)=2.11, p=.15\right)$ or Islamophobia $\left(R^{2}=.004 ; F(1,52)=2.12, p=.66\right)$. However, we did observe that the frequency of paranoid thoughts, conversely, did predict the variance of both cultural mistrust of Muslims $\left(R^{2}=.24, F\right.$ $(1,52)=15.94, p<.001)$ and Islamophobia $\left(R^{2}=.15 ; F(1,52)=9.28, p=.004\right)$. Given that death anxiety was moderately correlated with the frequency of paranoid thoughts $(r=.34)$ and significantly correlated with anti-Muslim prejudice, we decided to insert the frequency of paranoid thoughts in this model as a possible mediator of the relationship between death anxiety and anti-Muslim prejudice.

Figure 1 shows this model and standardised beta values. The model fits the data well, $\chi^{2}(53)$ $=30.80, p<.001$; with a Bentler-Bonett Normed Fit Index (BBFI) of .89 and a Comparative Fit Index (CFI) of .41, both of which meet the threshold of .90 to show a good fit. The Root Mean Square Error of Approximation (RMSEA) was less than the threshold of .10; RMSEA $=.03$. Death anxiety did not have a significant direct effect on anti-Muslim prejudice $(\beta=.04, p=$ n.s. for cultural mistrust of Muslims and $\beta=-.077, p=$ n.s. for Islamophobia, respectively). However, in support of our hypothesis, an indirect path was significant - death anxiety did have statistically significant indirect effects on anti-Muslim prejudice through the mediator variable of the frequency of paranoid thoughts $\beta=.16$, Sobel's $Z=2.15, p=.031$ for the cultural mistrust of Muslims and $\beta=.14$, Sobel's $Z=2.15, p=.031 Z=2.03, p=.041$ for Islamophobia, respectively. This suggests that paranoia is a mediator of the relationship between death anxiety and anti-Muslim prejudice.

Table 1. Terrorist news vs. neutral news conditions' effects on death anxiety, state social paranoia and antiMuslim prejudice.

\begin{tabular}{|c|c|c|c|c|c|c|c|}
\hline & \multicolumn{2}{|c|}{$\begin{array}{l}\text { Terrorist news } \\
\text { condition }\end{array}$} & \multicolumn{2}{|c|}{$\begin{array}{l}\text { Non-terrorist } \\
\text { news condition }\end{array}$} & \multirow[b]{2}{*}{$F$} & \multirow[b]{2}{*}{$p$} & \multirow[b]{2}{*}{$95 \% \mathrm{CI}$} \\
\hline & $M$ & SD & $M$ & SD & & & \\
\hline State social paranoia & 46.33 & 9.23 & 44.61 & 7.48 & .53 & n.s. & $(43-48)$ \\
\hline Death anxiety & 56.93 & 11.9 & 55.61 & 13.1 & .15 & n.s. & $(53-60)$ \\
\hline Cultural mistrust of Muslims & 61.37 & 40.5 & 56.35 & 36.8 & .22 & n.s. & $(49-70)$ \\
\hline Islamophobia & 28.37 & 12.3 & 29.35 & 12.9 & .08 & n.s. & $(25-32)$ \\
\hline
\end{tabular}


Table 2. Correlations between the main variables.

\begin{tabular}{|c|c|c|c|c|c|c|c|c|}
\hline & $\begin{array}{l}\text { Paranoia } \\
\text { frequency }\end{array}$ & $\begin{array}{l}\text { Paranoia } \\
\text { conviction }\end{array}$ & $\begin{array}{c}\text { Paranoia } \\
\text { distress }\end{array}$ & $\begin{array}{l}\text { Death } \\
\text { anxiety }\end{array}$ & Islamophobia & $\begin{array}{l}\text { Cultural mistrust } \\
\text { of Muslims }\end{array}$ & $\begin{array}{l}\text { Negative implicit } \\
\text { attitudes towards } \\
\text { Muslims }\end{array}$ & $\begin{array}{c}\text { State social } \\
\text { paranoia }\end{array}$ \\
\hline Paranoia frequency & & $.36^{* *}$ & $.31 *$ & $.34 * *$ & $.39 * *$ & $.49 * *$ & .13 & .20 \\
\hline Paranoia distress & $.31^{* *}$ & .17 & & $.28^{*}$ & -.05 & .07 & .06 & $.48^{* *}$ \\
\hline Death anxiety & $.33^{*}$ & .04 & $.28^{*}$ & & .06 & .20 & .05 & $.37 * *$ \\
\hline Islamophobia & $.39 * *$ & .21 & -.05 & .06 & & $.72 * *$ & $-.24^{+}$ & -.07 \\
\hline $\begin{array}{l}\text { Cultural mistrust of } \\
\text { Muslims }\end{array}$ & $.49^{* *}$ & .04 & .07 & .20 & .72 & & -.11 & -.05 \\
\hline State social paranoia & .20 & .19 & $.48 * *$ & $.37 * *$ & -.07 & -.05 & .07 & \\
\hline
\end{tabular}

$* * p<.005$.

${ }^{*} p<.05$. 


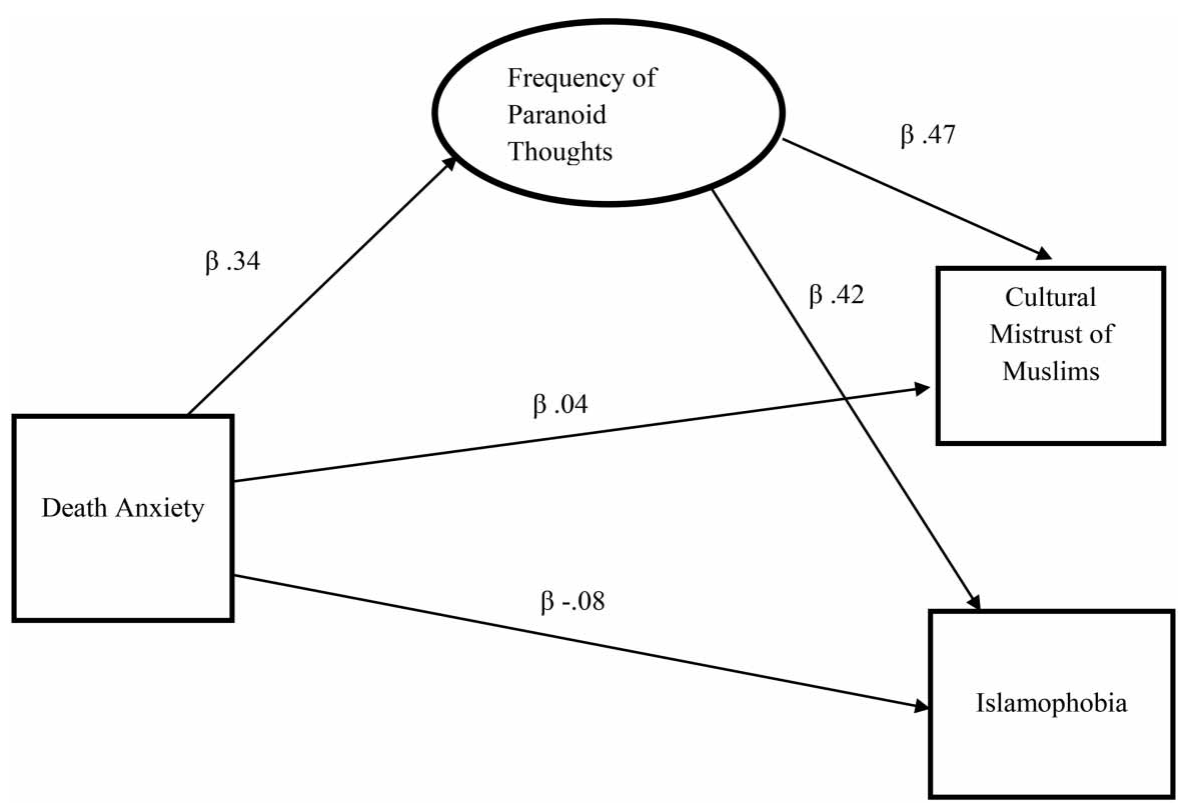

Figure 1. Pathway analysis model with death anxiety as the IV and the frequency of paranoid thoughts as a mediator of anti-Muslim prejudice.

\section{Experiment 2}

The aim of experiment 2 was to corroborate one of the main findings of experiment 1, namely that paranoia is associated with out-group prejudice. We wanted to test whether paranoid traits would become salient in a context of competition, and whether this would stimulate negative thoughts, feelings and perceptions about a member of a salient out-group (i.e., a Muslim player).

\section{Method}

\section{Participants}

Ninety-four De Montfort University and Leicester University undergraduate students were recruited to take part in this study. There were more females $(n=67)$ than males $(n=27)$ in this sample. Nonetheless, there were no statistically significant differences between the genders concerning baseline and post-experimental trait paranoia. The age range of participants was $18-58(M=22.54, \mathrm{SD}=5.59)$.

In contrast to experiment 1 , this study presented not only a negative and neutral news condition, but also a positive news condition that depicted Islam in a positive light. This sample included 48 Christians, 10 Hindus, 22 atheists and 14 unspecified religions. Participants of different religious backgrounds and atheists were evenly and randomly distributed between the three news conditions -31 participants watched the negative news clip, 27 the positive news clip and 36 watched the neutral news clip.

\section{Instruments}

In addition to the State Social Paranoia Scale (Freeman et al., 2007), we used the following questionnaires. 
The General Paranoia Scale (Fenigstein \& Vanable, 1992) aims to assess trait paranoia in a non-clinical, student population. The scale consists of 20 items, for example, "Someone has been trying to influence my mind". Scoring is presented on a five-point Likert Scale, and can range from 20 to 100, with higher scores indicating more paranoid thoughts. The internal reliability of the scale was excellent, $\alpha=.90$.

The Perceptions about the Competing Player Questionnaire (Lopes \& Pinto-Gouveia, 2012, 2013) explores two aspects: (1) how participants are feeling and what kind of thoughts they have concerning their game performance, e.g., if they thought they were competent or incompetent or if they were frustrated or happy; and (2) the thoughts and feelings that participants had about the competing Muslim player (i.e., positive or negative). This scale has been adapted from the scale Cognitive Perceptions and Emotional Responses (Dutton \& Brown, 1997). The scale consists of 14 items, for example, "The player made me feel frustrated". Participants indicated their level of agreement on a seven-point Likert Scale. Scores are totalled and the higher the score, the more negative feelings and thoughts about the performance in the game and the more negative thoughts and feelings towards the Muslim competing player, that is, another form of contextual prejudice. The internal reliability of the scale was good, $\alpha=.81$.

\section{Experimental procedure}

Participants were asked to complete the baseline measure of trait paranoia and then they were randomly assigned to the news conditions: negative Islamic portrayal (participants were exposed to a news report about the murder of Lee Rigby, a British soldier, in London at the hands of two Muslim extremists), positive Islamic portrayal (participants were exposed to a news report of a Muslim community helping to feed the homeless), and a neutral portrayal (the clip presented to participants was unrelated to Islam and similar to the one used in the previous study). After viewing the clips, participants were told that they were going to play an online game of checkers against a competing Muslim player.

The use of an online game of checkers was set up so that participants would fail against the Muslim competitor, and followed the procedures outlined by Dutton and Brown (1997), who examined how induced failure in the lab can lead to mood changes and affect self-esteem, thereby inducing self-serving biases. Social psychology research has used games such as cyberball (Williams, Yeager, Cheung, \& Choi, 2012) to induce feelings of exclusion, stress, negative cognitions about personal performance (Dutton \& Brown, 1997) and negative cognitions about other players and out-groups (Schaafsma \& Williams, 2012). Moreover, research has shown that induced failure in the lab is associated with depressive (Shah, O'Carrol, Rogers, Moffoot, \& Ebmeier, 1999) and paranoid thoughts (Lopes \& Pinto-Gouveia, 2012). Therefore, we expected this online game of checkers to induce stress in participants by artificially prompting their failure and poor performance compared to a competing Muslim player, and that this stressful experience would stimulate underlying negative cognitions about Muslims. Indeed, research has shown that failure in competitive games can induce paranoia and associated cognitive biases. Players may attribute personal failure to the competing player, express hostility towards the player and experience negative cognitions (Lopes \& Pinto-Gouveia, 2012).

The player profiles that were presented to players before the game started featured a picture of a Muslim young man/woman. Male players were told they were playing against the Muslim young man whereas, female players were told they were playing against the Muslim young woman to avoid gender bias. Participants were in fact playing against the computer. To render this more credible, the researcher pretended to telephone the competing player to check whether he/she was ready to begin. Before the game started, the players were told that the purpose of the game was to win against the competing player and that they had 10 minutes to 
do so. They were also told that most university students win the game. In fact, the game was set to a high difficulty setting to induce failure. Participants also had to state their level of experience of playing checkers and online games. After this they were given a practice trial that lasted 5 minutes, and then they played the game for 10 minutes. After the game, they were given the outcome questionnaires of State Social Paranoia Scale, the General Paranoia Scale and the Perceptions About the Competing Player Questionnaire to fill in. Participants were debriefed and thanked for their participation.

\section{Results}

We first computed the differences between the scores on general paranoia (GP) at baseline and post-experiment. The positive scores indicate a decrease on trait paranoia between baseline and post-experiment.

Preliminary ANOVA analyses showed that the British religious individuals presented more trait GP both at baseline and post-experiment with the Christian participants presenting the highest scores (Christians: GP baseline, $M=43.77$, $\mathrm{SD}=14.06$; GP post-experiment, $M=$ 42.73, $\mathrm{SD}=15.07$; followed by the Hindu participants: GP baseline, $M=43.20, \mathrm{SD}=13.12$, GP post-experiment, $M=41.30, \mathrm{SD}=11.58$ and other religions: $\mathrm{GP}$ baseline, $M=43.00, \mathrm{SD}=$ 16.71 and GP post-experiment, $M=42.71, \mathrm{SD}=16.56$ ) than the British atheists (GP baseline: $M=35.90, \mathrm{SD}=10.24$; GP post-experiment: $M=35.22, \mathrm{SD}=9.91)$. Nonetheless, the effects of religion in both baseline and post-experiment trait paranoia were statistically non-significant $(F(3,93)=1.78, p=.16$ and $F(4,93)=1.57, p=.20$, respectively). The differences between the Christians who scored the highest on GP and the atheists who scored the lowest were statistically significant, $t(68)=2.44, p=.022$ for baseline paranoia and $t(68)=2.13, p=.037$ for postexperimental paranoia, respectively. This meant that British Christians manifested significantly more baseline and post-experimental paranoia than the atheists.

Moreover, as expected, British religious individuals also manifested more state social paranoia following the experimental conditions, with the Hindus manifesting the highest scores on state social paranoia $(M=48.70, \mathrm{SD}=6.39)$ followed by other religions $(M=46.42, \mathrm{SD}=$ 10.36) and Christians $(M=45.41, \mathrm{SD}=9.60)$ compared to the atheists $(M=42.13, \mathrm{SD}=5.99)$. As observed previously, this effect was statistically non-significant $(F(3,93)=1.55, p=.21)$. However, the differences between the Hindus who scored the highest on state social paranoia and the atheists who scored the lowest were statistically significant $t(30)=2.84, p=.008$. This meant that Hindus were also manifesting more state social paranoia than atheists. However, there was no main effect of news conditions on the level of trait paranoia scores from baseline to post-experiment $(F(2,93)=1.26, p=.29)$.

Christian participants manifested the most negative perceptions of their game performance and of the Muslim competing player $(M=44.14, \mathrm{SD}=13.59)$ followed by the atheists $(M=$ $42.41, \mathrm{SD}=15.47)$ and Hindus $(M=40.50, \mathrm{SD}=12.77)$. In the negative news condition, participants manifested more negative perceptions of game performance and of the Muslim competing player $(M=44.55, \mathrm{SD}=13.48)$ than in the positive and neutral news conditions $(M=40.45, \mathrm{SD}=$ 15.79 and $M=41.12, \mathrm{SD}=12.26$, respectively) but this effect was non-significant $(F(2,93)=.62$, $p=.54$ ). In conclusion, although both religious people and those who viewed negative news of Islam exhibited more trait paranoia and more negative perceptions of the Muslim competing player, these trends were not powerful enough to be statistically significant. Nevertheless, Christians and Hindus both manifested more GP and state social paranoia than atheists.

We also performed correlations to examine the relationships between the main variables. As to be expected, baseline trait paranoia was positively correlated with state social paranoia $(r=.58$, $p<.001)$ and with the perceptions of the game and of the competing Muslim player score 
$(r=.29, p=.005)$. This suggested that the more trait paranoia at baseline, the more post-experimental state social paranoia and the more negative perceptions of the competing Muslim player. There was, however, no significant correlation between state social paranoia and perceptions of the competing Muslim player score. A linear regression showed that baseline trait paranoia was a statistically significant predictor, accounting for around $29 \%$ of the variance of the negative perceptions of Muslim player score $\left(R^{2}=.08, F(1,93)=8.46, p=.005\right)$. Moreover, when state social paranoia was added to the model, we observed that this variable did not add any value to the prediction $(\beta=.003 ; t=.017, p=.99)$.

\section{Discussion}

This study tested the effects of exposure to (Islamist) terrorism news on prejudice towards Muslims, state social paranoia and death anxiety and explored the role of paranoid thinking in predicting cultural mistrust of Muslims and Islamophobia. The results showed that there was no association between news condition and the levels of state social paranoia, death anxiety or prejudice against Muslims. This does not support our first hypothesis and failed to replicate Das et al.'s (2009) study of Islamophobia in the Netherlands. Although the main manipulation from the first study did not succeed in impacting the dependent measures of Islamophobia, there is existing evidence that the mass media have played an important role in influencing attitudes towards Muslims post-9/11 (see Cinnirella, 2014; Das et al., 2009; Sheridan, 2006). Moreover, our results suggest that exposure to terrorism news does not increase levels of paranoia, which is inconsistent with the existing empirical observation that violent events depicted in the media can increase paranoid beliefs and thoughts (Freeman \& Freeman, 2008).

Some tentative explanations for these findings can be offered. First, the media's depiction of Islamist terrorism has been particularly negative in the Dutch context, particularly in the aftermath of the murder of Theo van Gough (Meyer, 2008). Das et al.'s (2009) experiment was conducted soon after this high-profile terrorist incident in Holland and would therefore constitute a salient issue activated in participants' minds when exposed to the stimulus, whereas the London bombings occurred almost 10 years prior to our experiment and would therefore be less cognitively salient. In addition to this time lag, it is noteworthy that the research was conducted in the multicultural city of Leicester, where there are generally positive intergroup relations between the city's diverse ethnic and religious communities. ${ }^{1}$ Although the aim of the studies was to measure levels of Islamophobia in a laboratory setting, study participants naturally draw upon their own existing social representations about the stimuli (Parker, 1987). In view of the multicultural character of Leicester, it is possible that our sample did not produce the same levels of Islamophobia that have been observed in more varied British samples (Cinnirella, 2014).

Second, Chadwick, Birchwood, and Trower (1996) claim that environmental influences are not the root cause of paranoia but rather the genetic make-up of the individual - environmental factors make little contribution to altering one's neurochemical state. Trower and Chadwick (1995) substantiate this claim by pointing to the high rate of hereditary illness in clinical populations, and a $40 \%$ concordance rate among monozygotic twins with paranoia. Moreover, research has shown the prevalence of a paranoid personality type in non-clinical populations, which might have more explanatory power than environmental factors (Fenigstein \& Vanable, 1992). For example, research by Livesley (1995) suggests that some individuals possess certain personality traits which are conducive to paranoid tendencies - such individuals remain in a state of sub-clinical paranoia despite environmental factors. The results of the present study would support this perspective as in the first experiment those participants who scored high on the paranoid checklist prior to the news condition proportionately scored high on the State Social Paranoia Scale 
(following the news condition). This suggests that these individuals exhibit a paranoid schema that may be influenced by their personality traits and genetic make-up.

The results of our second experiment support the work of Trower and Chadwick (1995) and Livesley (1995) that demonstrates the presence of trait paranoia in a non-clinical population. We found out that trait paranoia is a significant predictor of out-group prejudice as measured by the negative perceptions that non-Muslim participants had concerning the Muslim out-group. Our results are also consistent with social psychological theories of prejudice that suggest that when individuals of different groups compete with each other, they will manifest in-group favouritism bias and out-group derogation, as well as perceive threat from the members of the out-group (Hewstone, Rubin, \& Willis, 2002). Moreover, when individuals of different groups are put in a situation in which they have to compete with each other their paranoid tendencies will be salient, particularly when they need to compete with a member of a very salient out-group that is represented socially as one that people usually have to be suspicious of and feel threatened by, such as Muslims in a climate of Islamophobia (Cinnirella, 2014). Paranoid trait tendencies led to an activation of negative schemas of Muslims characterised by the presence of negative thoughts about the competing Muslim.

In support of our second hypothesis, our results demonstrate that paranoid thinking is a reliable predictor of prejudice towards Muslims. These results make a novel contribution to the understanding of TMT by suggesting that paranoia can mediate the effect of death anxiety on prejudice. For instance, theories, such as the Meaning Management Theory and Self-determination Theory, shift the emphasis from minimising terror to maximising meaning-making (Ryan \& Deci, 2004; Wong \& Tomer, 2011). Kirkpatrick and Navarrete (2006) argue from an evolutionary psychological perspective that it is implausible that the defence of in-group world views has evolved as the solution to managing death anxiety as a terror management system. Many studies have identified other prime causal factors underlying prejudice - Heaven and St. Quintin (2003) demonstrated that personality factors (e.g., a strong affiliation with nationalism) predicted prejudice. In a similar vein, the present study demonstrates that paranoid thinking is a significant predictor of Islamophobic prejudice and that paranoia is a significant mediator of the impact of death anxiety on prejudice.

This complements existing research which has found a close association between paranoia and prejudice (Biassey, 1972; Jamal \& Naber, 2008). This, therefore, suggests that prejudice, specifically cultural mistrust and Islamophobia, may arise from persecutory beliefs towards a perceived threat to one's own safety - in context of our study, Muslims (cf. Jamal \& Naber, 2008). Individuals with high levels of paranoia tend to harbour suspicion and mistrust of others (Kramer, 1998), and subjectively accentuate risk despite low objective risk (Abbot, 1914). This may explain the link between heightened paranoia and cultural mistrust towards Muslims and Islamophobia in the context of terrorism - individuals may erroneously accentuate the risk that Muslims pose to their safety, due to their own paranoid tendencies (Freeman \& Freeman, 2008). Our findings clearly suggest that paranoid thinking shapes our attitudes towards "Significant Others" which are perceived to threaten, in one way or another, the integrity, purity and independence of the in-group in a significant way (Triandafyllidou, 2001). Having a paranoid schema of the social world predisposes individuals to be extremely suspicious of out-groups (and especially of those that are socially represented as posing a threat) (Fenigstein \& Vanable, 1992). In the aftermath of high-level terrorist attacks and the more recent atrocities committed by the so-called Islamic State of Iraq and Syria, the Western media is replete with representations that construct Muslims as a legitimate target for suspicion and mistrust (Jaspal \& Cinnirella, 2010) and, as such, is a fertile breeding ground for paranoia and prejudice in societal thinking.

Complementing the existing TMT accounts of prejudice, study 1 showed that the frequency of paranoid thoughts functions as a mediator of the relationship between death anxiety and anti- 
Muslim prejudice. Research into paranoia in non-clinical populations can contribute to our understanding of this finding (Ellet, Lopes, \& Chadwick, 2003). For example, this research has shown that paranoid thoughts in non-clinical populations are fleeting and context-dependent. Similarly, empirical research in clinical psychology (Ellet et al., 2003) indicates that non-clinical paranoid individuals will respond to situations that are threatening to the self by employing strategies, such as cognitive restructuring and re-appraisal, to impede the onset of a rigid paranoid schema consisting of stable and unshakable paranoid beliefs commonly observed in individuals who suffer from paranoid schizophrenia. As such, the impact of paranoid thoughts in the non-clinical paranoid individual is less strong emotionally than in the paranoid schizophrenic because the paranoid individual will quickly re-structure their experience and question their thoughts.

However, if individuals feel threatened (due to media representations of terrorist threat, for instance), they may develop a paranoid schema as a defensive coping strategy (Bentall, Kinderman, $\&$ Kaney, 1994). This may explain why paranoia mediates the relationship between death anxiety and anti-Muslim prejudice. First, it seems feasible that death anxiety may lead to fear about the ill intentions of others who may bring about harm. From a cognitive perspective, both are erroneous interpretations of social situations - one may perceive threat in other people's actions without sufficient basis, for instance. Second, because death anxiety is more strongly associated with the self as being finite and paranoia with the notion that the others will harm the self, it seems reasonable to argue that, for death anxiety to have an impact on out-group prejudice, paranoia needs to be present. In other words, paranoia may be the missing link. This would explain the presence of negative and biased attitudes towards the Muslim out-group. However, because these particular findings are based on a cross-sectional design, we could not establish causality and examine whether it is paranoia that leads to death anxiety or vice versa. This study, nevertheless, opens up an important avenue of research that could explore the relationship between the two variables and their impact on anti-Muslim prejudice.

Interestingly, negative implicit attitudes towards Muslims did not predict anti-Muslim prejudice, which cast some doubt on the validity of the IAT. Indeed, it has been argued that the IAT, instead of measuring implicit attitudes, simply measures constructs such as salience of attributes (Rothermund \& Wentura, 2004) or cultural knowledge (Arkes \& Tetlock, 2004). Furthermore, the consistency of the IAT has been questioned, since participants who undertake the test multiple times tend to contribute differing results (Tierney, 2008). Future research should examine the role of paranoia in prejudice more fully by exploring trait aspects of paranoia and the relationship between paranoia and the media. Can paranoia be shaped or is this entirely determined by the genetic make-up? This would allow us to further elucidate the inter-relations between paranoia and prejudice. Historically, a state of paranoia has led to the irrational belief that one's ingroup faces an existential threat from a specific (often vulnerable) out-group. A chilling example of this psychological process is the age-old persecution of the Jewish people which culminated in the Holocaust. Accordingly, it is important to research how paranoid fears and a paranoid predisposition may lead to prejudice. It is hoped that these preliminary, but suggestive, experimental studies will encourage further research in this important area.

\section{Note}

1. BBC News, http://news.bbc.co.uk/1/hi/england/1357865.stm.

\section{References}

Abbot, E. S. (1914). What is paranoia? The American Journal of Psychiatry, 71(1), 29-40. doi:10.1176/ajp. 71.1.29 
Arkes, H. R., \& Tetlock, P. E. (2004). Attributions of implicit prejudice, or "would Jesse Jackson 'fail' the Implicit Association Test?" Psychological Inquiry, 15, 257-278. doi:10.1207/s15327965pli1504_01

Bentall, R. P., Kinderman, P., \& Kaney, S. (1994). The self, attributional processes and abnormal beliefs: Towards a model of persecutory delusions. Behavioural Research Therapy, 32(3), 331-341. doi:10. 1016/0005-7967(94)90131-7

Bhat, S. K. (2007). The paranoia of prejudice. The Journal of Clinical Psychiatry, 68(6), 968-969. doi:10. 4088/jcp.v68n0623

Biassey, E. L. (1972). Paranoia and racism in the United States. Journal of the National Medical Association, 64(4), 353-358.

BPS Ethics Committee. (2009). Code of ethics and conduct. Leicester: British Psychological Society.

Chadwick, P., Birchwood, M., \& Trower, P. (1996). Cognitive therapy for delusions, voices and paranoia. Chichester: Wiley.

Cinnirella, M. (2014). Understanding Islamophobic prejudice: The interface between identity process theory and intergroup threat theory. In R. Jaspal \& G. M. Breakwell (Eds.), Identity Process Theory: Identity, social action and social change (pp. 253-269). Cambridge, MA: Cambridge University Press.

Cinnirella, M., Leman, P. J., Hastings, K., \& Whitbread, N. (2009). Can fear of terrorism exacerbate prejudice? Threats to the nation and Islamophobia (Working Paper). Royal Holloway, University of London.

Combs, D. R., Penn, D. L., Cassisi, J., Michael, C., Wood, T., Wanner, J., \& Adams, S. (2007). Perceived racism as a predictor of paranoia among African Americans. Journal of Black Psychology, 32, 87-104. doi:10.1177/0095798405283175

Das, E., Bushman, B. J., Bezemer, M. D., Kerkhof, P., \& Vermeulen, I. E. (2009). How terrorism news reports increase prejudice against out-groups: A terror management account. Journal of Experimental Social Psychology, 45, 453-459. doi:10.1016/j.jesp.2008.12.001

Dutton, K. A., \& Brown, J. D. (1997). Global self-esteem and specific self-views as determinants of people's reactions to success and failure. Journal of Personality and Social Psychology, 73, 139-148. doi:10. 1037/0022-3514.73.1.139

Ellet, L., Lopes, B., \& Chadwick, P. (2003). Paranoia in a non-clinical population of college students. The Journal of Nervous and Mental Disease, 191, 425-430. doi:10.1097/01.nmd.0000081646.33030.ef

Fenigstein, A., \& Vanable, P. A. (1992). Paranoia and self-consciousness. Journal of Personality and Social Psychology, 62(1), 129-138. doi:10.1037//0022-3514.62.1.129

Freeman, D., \& Freeman, J. (2008). Paranoia: The 21st century fear. Oxford: Oxford University Press.

Freeman, D., Garety, P. A., Bebbington, P. E., Smith, B., Rollinson, R., Fowler, D., ... Dunn, G. (2005). Psychological investigation of the structure of paranoia in a non-clinical population. The British Journal of Psychiatry, 186, 427-435. doi:10.1192/bjp.186.5.427

Freeman, D., Pugh, K., Green, C., Valmaggia, L., Dunn, G., \& Garety, P. (2007). A measure of state persecutory ideation for experimental studies. The Journal of Nervous and Mental Disease, 195(9), 781-784. doi:10.1097/nmd.0b013e318145a0a9

Gilbert, P., Boxall, M., Cheung, M., \& Irons, C. (2005). The relation of paranoid ideation and social anxiety in a mixed clinical population. Clinical Psychology and Psychotherapy, 12, 124-133. doi:10.1002/cpp. 438

Greenberg, J., Pyszczynski, Y., \& Solomon, S. (1986). The causes and consequences of a need for selfesteem: A Terror Management Theory. In R. Baumeister (Ed.), Public self and private self (pp. 189212). New York, NY: Springer.

Greenberg, J., Schimel, J., Martens, A., Solomon, S., \& Pyszczynski, T. (2001). Sympathy for the devil: Evidence that reminding whites of their mortality promotes more favorable reactions to white racists. Motivation and Emotion, 25, 113-133.

Greenwald, A. G., McGhee, D. E., \& Schwartz, J. K. L. (1998). Measuring individual differences in implicit cognition: The Implicit Association Test. Journal of Personality and Social Psychology, 74, 1464-1480. doi:10.1037/0022-3514.74.6.1464

Heaven, P. C. L., \& St. Quintin, D. (2003). Personality factors predict racial prejudice. Personality and Individual Differences, 34(4), 625-634. doi:10.1016/s0191-8869(02)00046-6

Hewstone, M., Rubin, M., \& Willis, H. (2002). Intergroup bias. Annual Review of Psychology, 53, 575-604. doi:10.1146/annurev.psych.53.100901.135109

Jamal, A. A., \& Naber, N. C. (2008). Race and Arab Americans before and after 9/11: From invisible citizens to visible subjects. New York, NY: Syracuse University Press.

Jaspal, R., \& Cinnirella, M. (2010). Media representations of British Muslims and hybridised threats to identity. Contemporary Islam: Dynamics of Muslim Life, 4(3), 289-310. doi:10.1007/s11562-010-0126-7 
Johnson, J. D., Olivo, N., Gibson, N., Reed, W., \& Ashburn-Nardo, L. (2009). Priming media stereotypes reduces support for social welfare policies: The mediating role of empathy. Personality and Social Psychology Bulletin, 35(4), 463-476. doi:10.1177/0146167208329856

Kirkpatrick, L. A., \& Navarrete, C. D. (2006). Reports of my death anxiety have been greatly exaggerated: A critique of Terror Management Theory from an evolutionary perspective. Psychological Inquiry, 17(4), 288-298. doi:10.1080/10478400701366969

Kramer, R. M. (1998). Paranoid cognition in social systems: Thinking and acting in the shadow of doubt. Personality and Social Psychology Review, 2(4), 251-275. doi:10.1207/s15327957pspr0204_3

Lee, A. S., Gibbons, J. A., Thompson, J. M., \& Timani, H. S. (2009). The Islamophobia Scale: Instrument development and initial validation. The International Journal for the Psychology of Religion, 19, 92 105. doi:10.1080/10508610802711137

Lester, P. M., \& Ross, S. D. (2003). Images that injure: Pictorial stereotypes in the media. Westport, CT: Praeger.

Livesley, W. J. (1995). The DSM-IV personality disorders. New York, NY: Guilford Press.

Lopes, B., \& Pinto-Gouveia, J. (2012). How do non-clinical paranoid and socially anxious individuals react to failure? The role of hostility and state anxiety. Journal of Forensic Research, 3, 144. doi:10.4172/ 2157-7145.1000144

Lopes, B., \& Pinto-Gouveia, J. (2013). How do non clinical paranoid individuals and socially anxious individuals react to negative vs. positive affective laden sounds? International Journal of Applied Psychology, 3(3), 63-73. doi:10.5923/j.jiap.20130303.05

McNaughton-Cassill, E., Novian, D. A., Holmes, T. L., \& Smith, T. L. (2009). Emotional stress and coping in response to television news coverage of the 9/11 terrorist attacks. Journal of Media Psychology, 14(1), $16-26$.

Meyer, R. (2008). The assassination of Theo van Gogh: From social drama to cultural trauma: Politics, history, culture. Durham, NC: Duke University Press.

Parker, I. (1987). 'Social representations': Social psychology's (mis) use of sociology. Journal for the Theory of Social Behaviour, 17(4), 447-469. doi:10.1111/j.1468-5914.1987.tb00108.x

Poole, E. (2002). Reporting Islam: Media representations and British Muslims. London: I.B. Tauris.

Richardson, J. E. (2004). (Mis)representing Islam: The racism and rhetoric of British broadsheet newspapers. Amsterdam: John Benjamins.

Rippy, A. E., \& Newman, E. (2006). Perceived religious discrimination and its relationship to anxiety and paranoia among Muslim Americans. Journal of Muslim Mental Health, 1(1), 5-20. doi:10.1080/ 15564900600654351

Rothermund, K., \& Wentura, D. (2004). Underlying processes in the Implicit Association Test (IAT): Dissociating salience from associations. Journal of Experimental Psychology: General, 133(2), 139165. doi:10.1037/0096-3445.133.2.139

Ryan, R. M., \& Deci, E. L. (2004). Avoiding death or engaging life as accounts of meaning and culture: Comment on Pyszczynski et al. (2004). Psychological Bulletin, 130, 473-477. doi:10.1037/00332909.130.3.473

Saeed, A. (2007). Media, racism and Islamophobia: The representation of Islam and Muslims in the media. Sociology Compass, 1(2), 443-462. doi:10.1111/j.1751-9020.2007.00039.x

Schaafsma, J., \& Williams, K. D. (2012). Exclusion, intergroup hostility, and religious fundamentalism. Journal of Experimental Social Psychology, 48, 829-837. doi:10.1016/j.jesp.2012.02.015

Shah, P. J., O' Carrol, R. E., Rogers, A., Moffoot, A. F., \& Ebmeier, K. F. (1999). Abnormal response to negative feedback in depression. Psychological Medicine, 29(1), 63-72. doi:10.1017/ s0033291798007880

Sheridan, L. P. (2006). Islamophobia pre- and post-September 11 th, 2001. Journal of Interpersonal Violence, 21(3), 317-336. doi:10.1177/0886260505282885

Stephan, W. G., \& Stephan, C. W. (2000). An integrated threat theory of prejudice. In S. Oskamp (Ed.), Reducing prejudice and discrimination (pp. 23-46). Mahwah, NJ: Erlbaum.

Tajfel, H. (1982). Social psychology of intergroup relations. Annual Review of Psychology, 33, 1-39. doi:10. 1146/annurev.ps.33.020182.000245

Templer, D. I. (1970). The construction and validation of Death Anxiety Scale. The Journal of General Psychology, 82(2), 165-177. doi:10.1080/00221309.1970.9920634

Terrell, F., \& Terrell, S. L. (1981). An inventory to measure cultural mistrust among blacks. The Western Journal of Black Studies, 5(3), 180-184.

Tierney, J. (2008, November 17). In bias test, shades of gray. The New York Times. Retrieved from http:// www.nytimes.com/2008/11/18/science/18tier.html?_r=0 
Triandafyllidou, A. (2001). Immigrants and national identity in Europe. London: Routledge.

Trower, P., \& Chadwick, P. (1995). Pathways to defense of the self: A theory of two types of paranoia. Clinical Psychology: Science and Practice, 2(3), 263-278. doi:10.1111/j.1468-2850.1995.tb00044.x

Williams, K. D., Yeager, D. S., Cheung, C. K. T., \& Choi, W. (2012). User manual for cyberball (version 4.0) [Software]. Retrieved from http://www.icn.ucl.ac.uk/webspace/users/sblakemore/cyberball_exclude.swf Wong, P. T., \& Tomer, A. (2011). Beyond terror and denial: The positive psychology of death acceptance. Death Studies, 35(2), 99-106. doi:10.1080/07481187.2011.535377

Yum, Y. O., \& Schenck-Hamlin, W. (2005). Reactions to $9 / 11$ as a function of terror management and perspective taking. Journal of Social Psychology, 145, 265-286. doi:10.3200/socp.145.3.265-286 